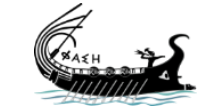

journal.phaselis.org
PHAS KLIS

Issue V (2019)
Disiplinlerarası Akdeniz Araştırmaları Dergisi

Journal of Interdisciplinary Mediterranean Studies

\title{
MS I. ve VIII. Yüzyıllar Arasında Kuzeybatı Pisidia'da Hristiyanlık
}

\author{
The Christianity in Northwest Pisidia Between $1^{\text {st }}$ and $8^{\text {th }}$ \\ Centuries $A D$
}

\section{Gülcan KAŞKA}

(D) https://orcid.org/0000-0003-0566-3965

\section{Kansu EKici \\ (iD https://orcid.org/0000-0002-8252-1138}

open 2 access journals

The entire contents of this journal, Phaselis: Journal of Interdisciplinary Mediterranean Studies, is open to users and it is an 'open access' journal. Users are able to read the full texts, to download, to copy, print and distribute without obtaining the permission of the editor and author(s). However, all references to the articles published in the e-journal Phaselis are to indicate through reference the source of the citation from this journal.

Phaselis: Journal of Interdisciplinary Mediterranean Studies is a peer-reviewed journal and the articles which have had their peer reviewing process completed will be published on the web-site (journal.phaselis.org) in the year of the journal's issue (e.g. Issue IV: JanuaryDecember 2018). At the end of December 2018 the year's issue is completed and Issue V: January-December 2019 will begin.

Responsibility for the articles published in this journal remains with the authors.

cc) (7)(2) This work is licensed under a Creative Commons AttributionEY NC SA NonCommercial-ShareAlike 4.0 International License.

Citation G. Kaşka - K. Ekici, "MS I. ve VIII. Yüzyıllar Arasında Kuzeybatı Pisidia'da Hristiyanlık". Phaselis V (2019) 333-346. http://dx.doi.org/10.18367/Pha.19021

Received Date: 12.09.2019 | Acceptance Date: 21.11.2019

Online Publication Date: 25.12.2019

Editing Phaselis Research Project

www.phaselis.org 


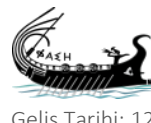

\title{
MS I. ve VIII. Yüzyıllar Arasında Kuzeybatı Pisidia'da Hristiyanlık
}

\author{
The Christianity in Northwest Pisidia Between $1^{\text {st }}$ and $8^{\text {th }}$ Centuries AD
}

\author{
Gülcan KAŞKA* - Kansu EKici ${ }^{* *}$
}

\begin{abstract}
Öz: Anadolu'nun birçok bölgesinde olduğu Pisidia Bögesi'nde de Hristiyanlı̆̆ın yayılmasında Aziz Paulus ve Aziz Barnabas öncü bir misyon üstlenmişlerdir. Azizler gittikleri yerlerde yeni dinin yayılması için müritlerini görevlendirmişlerdir. MS I. yüzyılda yayılmaya başlayan Hristiyanlık sonraki yüzyıllarda halk tarafından kabul görmüştür. Hristiyanlar, MS III. yüzyıl sonu ve IV. yüzyılın başında zulümlere uğramıştır. Ancak MS 313 yılında ilan edilen Milano Fermanı'yla Hristiyanlık diğer dinlerle eşit statüye kavuşmuş ve Theodosius döneminde ise imparatorluğun resmi dini olmuştur. Bununla birlikte Hristiyanların kendi aralarında farklı görüşler meydana gelmiş bu görüş ayrılıklarını gidermek için sık sık konsiller düzenlenmiştir. Bu konsillere Pisidia Bölgesi'ndeki kentlerden de temsilciler gönderilmiştir.
\end{abstract}

Anahtar sözcükler: Philippus Arabs, L. Egnatius Victor Lollianus, Pontus et Bithynia, Nikomedeia, Ağırlık Yazıtı

Abstract: As in many parts of Anatolia, in the region of Pisidia, St. Paulus and St. Barnabas have undertaken a leading mission in the spread of Christianity. The saints assigned their disciples to spread the new religion where they went. Christianity, which began to spread in the ${ }^{\text {st }}$ century, was accepted by the people in the following centuries. At the end of the $\mathrm{III}^{\text {rd }}$ century and the beginning of the IV $\mathrm{V}^{\text {th }}$ century, the Christians were murdered with persecutions. But Christians, the Milan Edict which was proclaimed in 313, gained equal status with other religions and then became the official religion in time of Theodosius. However, there were different views among Christians, the Christians have often appointed councils to remedy these disagreements. Representatives from the cities of Pisidia were sent to these councils.

Keywords: Pisidia, Christianity, Seleucia, Apollonia, Synod

Yahudiliğin küçük bir kolu olarak Ortadoğu'da ortaya çıkan Hristiyanlık zamanla bu dine mensup kişiler sayesinde evrensel bir yapıya bürünmüştür. Bu evrensel yapıya kavuşmasında ve dinin yayılmasında Aziz Paulus ile diğer azizlerin etkisi büyük olmuştur. Aziz Paulus ve arkadaşları bu dini yayarken öncelikle vatanlarından çeşitli nedenlerden dolayı imparatorluğun değişik bölgelerine sürülmüş Yahudileri kendilerine hedef kitle olarak seçmiştir ${ }^{1}$. Antikçağ misyonerlerinin bu faaliyetleri doğrultusunda birçok Yahudi bir yandan Hristiyanlığı benimserken diğer taraftan pek çoğu da Hristiyanlığa karşı büyük reaksiyonlar göstermiştir. Paulus ve ardıllarının misyonerlik faaliyetleri sırasında sadece Yahudiler değil, ayrıca paganlar da Hristiyanlığı kabul etmiştir.

* Dr. Öğr. Üyesi, Süleyman Demirel Üniversitesi, Fen Edebiyat Fakültesi, Arkeoloji Bölümü, Klasik Arkeoloji Anabilim Dalı, Isparta. gulcankaska@sdu.edu.tr | (D) https://orcid.org/0000-0003-0566-3965

** Dr. Öğr. Üyesi, Süleyman Demirel Üniversitesi, Fen Edebiyat Fakültesi, Tarih Bölümü, Orta Çağ Tarihi Anabilim Dalı Isparta. kansuekici@sdu.edu.tr | (D) https://orcid.org/0000-0002-8252-1138

1 Katar 2007, 333. 
Hristiyanlık yayıldığı ilk yüzyıldan itibaren kadınlar, yoksullar ve köleler arasında oldukça fazla kabul görmüştür. Zira toplum içinde oldukça fazla ezilen bu sosyal gruplar yüzyıllardır bekledikleri insanca muameleyi bu yeni din sayesinde elde etmişlerdir. Hristiyanlığın kadınlar, yoksullar ve kölelere getirdiği birtakım kazançlar bu sosyal tabakalar arasında Hristiyanlığın son derece hızlı bir şekilde yayılmasını sağlamıştır. Pagan inancında kadınların toplumsal rolü oldukça kısıtııydı. Birincil görevleri çocuk doğurmak ve ev işleriyle ilgilenmek olan kadın, soyun devamı için erkek çocuk doğurmak zorundaydı. Aksi durumda dünyaya gelen kız çocukları baba tarafından kabul edilmeyebilirdi. Üstelik kadınlar çok genç yaşta evlendiriliyordu. Ancak Hristiyanlık, kadınlara reva görülen bu uygulamalara şiddetle karşı çıkıyor, çocuğun cinsiyeti ne olursa olsun onu doğurmasını istiyordu. Kadınların evlenme yaşı 20'ydi². İşte yeni dinin kadınlara sunduğu birtakım özgürlükler onların bu dine geçmesini hızlandırmıştı. Bu kadınların ayrıca pagan erkeklerle de evlenmesine kilise tarafından izin verilmiş ancak doğacak çocukların Hristiyan öğretilerine göre yetiştirilmesi istenmiştir ${ }^{3}$. Hristiyanlığın oldukça rağbet gördüğü diğer iki grup olan yoksullar ve kölelerde durum farklı olmamıştır. Zira Hristiyanlığın, Tanrı katında yoksullar ile zenginlerin eşit olduğunu, efendi ile köle arasında herhangi bir farkın olmadığını dile getirmesi ${ }^{4}$ bu devrimci anlayışın o yüzyılda alt tabakalarda karşılık bulmasına neden olmuş ve bu sayede de Hristiyanlık geniş bir kitleye yayılmıştır. Yeni dinin bu sosyal gruplara getirdiği reformist değerler onların bu dini hızlı ve kolay kabul etmesini sağlamış ancak resmi otoritenin de tepkisine neden olmuştur. Çünkü Hristiyanlığın getirdiği yeni anlayış, hak ve özgürlükler imparatorluğun yapısıyla taban tabana zıttı. Sosyal gruplar arasında sarsılmaz bir statü farkı bulunuyordu. Hristiyanlığın getirdiği kardeşlik ve eşitlik ilkesi bu statü farkını yerle bir ediyordu. Bu nedenlerden ötürü başlangıçta küçük bir inanan kitlesine sahip olan Hristiyanlık zamanla imparatorluk topraklarında büyük bir nüfusa sahip olmuştur.

MS 50 ya da 51 yılında İsa'nın havarileri Kudüs'te toplanmış ${ }^{5}$ ve Hristiyanlığı, Yahudilikten ayırarak yeni bir din yaratma yoluna girmiş̧lerdir ${ }^{6}$. Bundan sonra Havariler, Kudüs'ten başlayarak, Anadolu, Hellas, Kuzey Afrika ve Roma'ya kadar yeni dini yaymaya çalışışlardır. İmparator Nero döneminde Roma'da Hristiyanlığın varlığı bilinmektedir. Zira Roma'da çıkan yangının sorumlusu olarak görüldükleri için sert şekilde cezalandırılmışlardır ${ }^{7}$. MS 67 yılında Hristiyan aleminin önde gelen azizleri Petrus ve Paulus, Roma'da idam edilmişlerdir. Roma'da MS I. yüzyıldan itibaren yayılan Hristiyanlık, MS I. ve II. yüzyıllarda eyaletler arasındaki yoğun ticari faaliyetler sonucunda topluluklar arası kültür alışverişi sayesinde giderek yayılmıştır.

Anadolu'nun pek çok bölgesinde olduğu gibi Pisidia'da da Hristiyanlığın yayılmasında Paulus ve Barnabas öncü bir misyon üstlenmiştir. Azizlerin Pisidia Bölgesi'ni ziyaret etmelerindeki en büyük etmenlerden biri burada yerleşmiş Yahudi nüfusudur. Zira Hellenistik Dönem'de Antiokhos III Megas (MÖ 222-187), Lydia ve Phrygia Bölgeleri'nde vuku bulan bir başkaldırıdan dolayı bu topraklara Babylonia'dan Yahudi nüfusu getirtmiştir ${ }^{8}$. Yahudiler, Pisidia Bölgesi'ne kadar yerleşmiş olmalıdır. Zira Paulus ve Barnabas'ı, bir Pisidia kenti olan Antiokheia'ya çeken

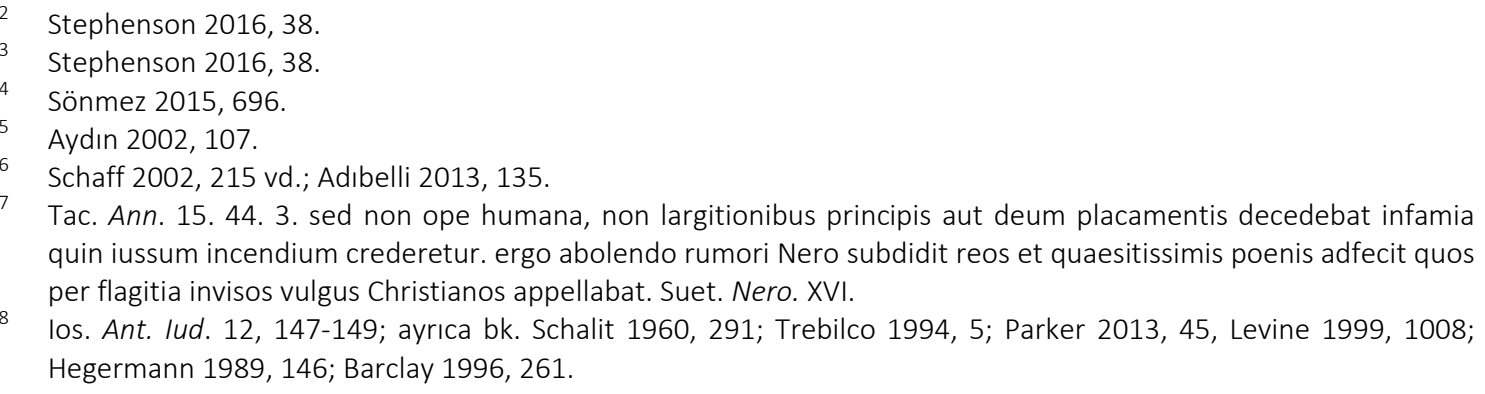


neden, antik kaynaklardan varlığından haberdar olduğumuz Yahudilerdir. Azizler bölgeye gelmeden önce ziyaret ettikleri Kıbrıs'ta buranın Valisi Pisidia Antiokheialı Q. Sergius Paullus vasıtasıyla şehirde Yahudi nüfusu 9 olduğunu öğrenmişlerdir. Misyonerlik faaliyetlerine 46-48 yıllarında başlayan azizler bu yolculuklarında Pisidia'daki Antiokheia'ya gelerek burada bir vaaz verdikten sonra Yahudi cemaati tarafından kentten kovulmuşlardır ${ }^{10}$. Bölgedeki diğer şehirlerde de Hristiyanlığın yayılması için müritlerini görevlendirmişlerdir. Bölgenin önemli kentlerinden olan Apollonia'da, Barnabas'ın kuzeni Marcus ${ }^{11}$, Seleukeia Sidera'da ise Paulus'un öğrencisi olan Artemon $^{12}$ tarafından ilk olarak Hristiyanlık yayılmaya çalışıımıştır. MS II. yüzyılda bölgede Hristiyanlaşma hareketlerinin resmi otoritenin tepkisine rağmen devam ettiği görülmektedir. Bölgenin önemli kentlerinden biri olan Apollonia'dan çıkmış bir aziz olan Zosimos, imparator Traianus döneminde, Domitianus'un valiliği sırasında orduda asker olmamak için silahlarını atarak kiliseye sığınmış, orada vaftiz olmuş ve birçok işkenceye maruz kalmıştır. Bundan sonra Konane'ye kaçan Aziz, üç gün boyunca aç ve susuz biçare kaldıktan sonra iki çocuk ona su ve ekmek taşımış ${ }^{13}$ ve nihayetinde burada şehit edilmiştir. Traianus döneminde Hristiyanlar üzerindeki kovuşturmalar devam etmiştir. Ayrıca imparator Traianus döneminde Hristiyan Aziz Ignatios (Ignatius) Mesih inancına sahip olmasından ötürü Roma'ya götürülüp Colosseum'da aslanların önüne atılmak suretiyle şehit edilmiştir ${ }^{14}$.

Hristiyanlığın ortaya çıkmasıyla yeni mezhepler de oluşmaya başlamıştır. MS II. yüzyılın sonlarına doğru Pisidia'da montanistlerin varlığı bilinmektedir. Konana ya da Komamalı Zotikos ve Apameialı lulianus'un kendi bölgelerindeki Montanistlere ${ }^{15}$ karşı hareket ettiği bilinmektedir ${ }^{16}$.

MS III. yüzyılda imparatorluk ekonomisi bozulmuş bunun yanı sıra sınırlar yağmacı barbar kavimlerinin akınlarına maruz kalmıştır. Bu yüzyılda imparatorluğu bekleyen tehlikelerden biri Got saldırılarıdır. Bu saldıııları önleyebilmek için Imparator Decius sefere çıkmış ancak ne yazık ki bu sefer kendi canına mal olmuştur. İmparator Decius (MS 249-251) hüküm sürdüğü süre boyunca dini alanda da bazı reformlar gerçekleştirmeye çalışmıştır. Bu doğrultuda tebaası altında yaşayan insanların tanrılara kurban kesmesini emretmiştir ${ }^{17}$. Ancak Hristiyanlar bu duruma aldırış etmemişler ve kendi dinlerinin gereklerini yerine getirmişlerdir. Bu yüzden imparator da Hristiyanlara karşı olumsuz tavır takınmış ve hükümranlığı zamanında da pek çok aziz şehit edilmiştir. Aziz Tryphon ve Respicius, Decius zamanında Nikaia'da şehit edilmişlerdir ${ }^{18}$. MS 253 yılında tahta geçen Valerianus döneminde de (MS 253-260) Hristiyanlara karşı menfi düşünceler devam etmiştir. Yönetimi sırasında özellikle kiliseler hedef noktası haline gelmiştir. Hristiyanların mülklerine el konmuş ve din adamları cezalandırılmıştır. Bu dönemde Kartaca'nın piskoposu Kyprianos, proconsul Galerius Maximus'un emriyle öldürülmüştür ${ }^{19}$. MS III. yüzyılda bu

Georg. Syn. chron. 404ç.

10 Acta Apost. 13. 50; ayrıca bk. Kaşka 2017, 24.

11 Vit. Proph. 141. 11-12; col 4. 10. 2-3.

12 BHG III. nr. 2047; ayrica bk. Mullen 2004, 105.

13 Syn. Ecc. Const. Synaxarium mensis lunii 20.1; ayrıca bk. Iversen, 2012, 109.

14 MS 35-107 yılları arasında yaşamış Antiokheialı (Antakya) aziz Ignatios'un Romalılara yazdığı mektuplara ilişkin olarak bk. Ignat. Scr. Eccl. Epist. 4. 5. 1.1 - 4. 5. 2 4.5.2 ; konuya ilişkin olarak ayrıca bk. Tiefenbach 2012, 28.

15 Montanus adlı bir Hıristiyan tarafından kurulduğu için müritleri de Montanist olarak adlandırılmıştır. Phrygia bölgesinde ortaya çıkmış bir Hıristiyanlık mezhebidir. Montanistler ahlaki davranışlar konusunda katı bir tutum göstermişler daha uzun süreli oruç tutmuşlar. Evlenmemeyi temizlik ve kutsalık olarak görmüşlerdir. Montanus ve Maximillia ile Priscilla bu mezhebin kurucularıdır (Şişman 2001, 5).

16 Euseb. Eccl Hist. 5. 16. 17. 1-12; ayrica bk. Ramsay 1897, 482; Mullen 2004, 92.

17 Fox 2006, 452; Rives 1999, 135.

18 Mullen 2004, 129; RE XIII. col. 724 s.v. Tryphon 13.

19 Gwynn 2015, 10. 
olumsuzluklara rağmen Hristiyanlık gelişimini sürdürmeye devam etmiştir. Bu yüzyılın ikinci yarısına tarihlendirilen, Pisidia Bölgesi'nde bulunan Apollonia'da ele geçmiş bir yazıtta Aurelia

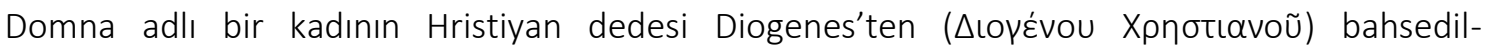
mektedir ${ }^{20}$. Ayrıca yine bu kentten ${ }^{21}$ ve Tymandos' $\tan ^{22}$ ele geçmiş epigrafik belgeler MS III. yüzyılda, bölgedeki Hristiyan nüfusunun varlığına işaret etmektedir. Bölgedeki mezar yazıtlarından anlaşıldığı üzere MS III. yüzyılda bozulan devlet ekonomisi nedeniyle halk mezar soyguncularına karşı birtakım önlemler almaya çalışmıştır. Pisidia bölgesi mezar yazıtlarında iki formulasyonun varlığı göze çarpmaktadır. Mezara zarar veren ya da bir başkasını koyan kentin yerel tapınağına belli bir miktarda para cezası ödemek zorundaydı ${ }^{23}$. Ancak MS III. yüzyııın ortasına doğru Eumeneia formülü adı verilen başka bir formulasyon yazıtlarda görülmektedir. Bu yazıtlarda Hristiyanlar, mezara karşı suç işleyecek kişileri, tanrıya hesap vermek zorunda olduğu konusunda uyarmaktadır ${ }^{24}$. Bu yüzyıl içinde kuzeybatı Pisidia Bölgesi'nde ele geçen Hristiyan yazıtları oldukça azdır.

MS III. yüzyılın son çeyreğinde imparator Diocletianus yönetimsel anlamda bazı değişikler yapmıştır. Öncelikle imparatorluğu Doğu ve Batı olmak üzere iki kısma ayırmıştır. Bu kısımların her birinin başında bir Augustus ve onun altında bir Caesar tayin etmiştir. Eyaletler imparator Diocletianus döneminde küçültülmüş ve Pisidia başlı başına bir eyalet konumuna yükseltilmiştir ${ }^{25}$. Diocletianus'un idari yapıda gerçekleştirdiği bu reformların ardından başka bir teşebbüsü de imparatorlukta yaşayan Hristiyanlara karşı olmuştur. Onun döneminde Hristiyanlara karşı zulümler daha da artmıştır. Öyle ki kilise tarihçisi Eusebius bu dönemde kiliselerin mülklerine el konulduğunu, kutsal kitaplarının toplatılıp yakıldığını ${ }^{26}$ ve Hristiyanların toplanmasının yasaklandığını aktarmaktadı2²7. Diocletianus'un Hristiyanlara karşı başlattığı kıyım nedeniyle hükümranlığı döneminde pek çok martyr hikayesi bilinmektedir. Anavatanları Pisidia Antiokheia yakınında bir köy olan Kalytoslu üç Hristiyan kardeş Alpheios, Zosimos ve Aleksandros'un şehadeti Diocletianus dönemine denk gelmektedir ${ }^{28}$. Ayrıca Diocletianus zamanında Philomelionlu üç martyr bilinmektedir. Neon, Nikon, Heliodoros adlı bu şahıslar Diocletianus zamanında Pisidia Antiokheia'sında şehit edilmişlerdir ${ }^{29}$. Diocletianus'un getirdiği Tetrarkhia sisteminin augustuslarından biri olan Maximinus Daia'nın (MS 270-313) Kolbasa'da bir fermanı bulunmuştur. Kolbasa'da bulunan fermanda Hristiyanların kendi inançlarında ısrar etmesi durumunda kentten ya da bölgeden ayrılmasına izin verileceği ve atalardan kalma dinlere sadık olanların ödüllendirilecekleri yazmaktadır ${ }^{30}$. MS 312'de Lycia - Pamphylia Eyaleti'nin sakinleri Maximinus'a, Hristiyanların,

MAMA 4. 221; ayrica bk. Mullen 2004, 90

MAMA 4. 201

Sterrett 1888a, 389 no. 564; Talloen 2015, 201.

Talloen 2015, 201.

24 Sterrett 1888a, 411, no. 604; Ramsay 1897, 557, no. 435. Antiokheia için bk. CIG 3980; SEG 6. 568; 582; SEG 52 1388; 571399 (4); Robinson 1926, 223, no. 46; 234, no. 69-70; Calder 1955, 26; Ruggieri - Filipović 2007, 465, no. 69-70. Talloen 2015, 201.

25 ILS 8932 = CIL III 13661; ayrıca bk. Kaşka 2017, 223. Belke - Mersich 1990, 79. Pisidia antikçağda genel olarak Isparta Burdur ve Antalya'nın kuzeyini kapsayan bölgedir. Diocletianus döneminde başlı başına bir eyalet haline getirilmiş ve daha sonraki yüzyıllarda imparatorluğun yaşadığı siyasi ve ekonomik çalkantılardan dolayı imparatorların aldığı önlemler nedeniyle Pisidia Eyaleti'nin sınırları da zaman içinde değişmiştir.

26 Euseb. Eccl Hist. 8. 2. 4.

27 Euseb. Eccl. Hist 9.10.8.

28 PG 136, 265D; TIB 7. 286; ayrica bk. Belke - Mersich 1990, 286 s.v. Kalytos, BHG; nr 63; Eyice 2002, 120; Mullen 2004, 97

29 Anastos 1967, 16-17; Eyice 2002, 120.

30 Mitchell 1988, 108; Sodini 2014, 374; Lenski 2016, 94. 
tanrıların barışını, toplumun huzurunu bozdukları gerekçesiyle bir dilekçe göndermişler ve Hristiyanlara karşı sert davranılmasını ve kentlerden gönderilmesini rica etmişlerdir ${ }^{31}$. Yöneticilerin bu dönemde Hristiyanlara karşı tutumu birbirinden faklıdır. Tetrarkhi sisteminin diğer iki yöneticisi olan Constantinus ve Licinius, MS 313 yılının Şubat'ında Milano Fermanı'nı imzalamasıyla Hristiyanlık diğer dinlerle eşit statüye kavuşmuştur ${ }^{32}$. MS 324'de Khrysopolis'te Licinius ve Constantinus arasında gerçekleşen savaştan sonra imparatorluğun tek hâkimi Constantinus olmuştur.

Constantinus'un belli bir Hristiyanlık yorumunu kabul etmesiyle mezhep ayrımıyla ilgili teolojik tartışmalar siyasi arenaya kaymış3 ${ }^{33}$ ve Hristiyanlar arasındaki mezhep ayrımları şiddetlenmeye başlamıştır. İskenderiye (Mısır) kilisesinde görev yapan Arius'un fikirleri insanlar arasında geniş yankı bulmuş ve bu fikirler giderek imparatorluk topraklarında yayılmaya başlamıştır. Arius'un görüşlerini kabul edilemez bulan din adamları, onun görüşlerine şiddetle karşı çıkmıştır. MS 325 yılında Constantinus tarafından Hristiyanlık içinde bazı konuları tartışmak için düzenlenen Nikaia Konsili'nin ana gündemi başta Aryanizm ${ }^{34}$ olmak üzere diğer ayrılıkçı gruplar ve onların yarattığı sorunlardır ${ }^{35}$. Pisidia Bölgesi'nde yer alan kentlerden biri olan Apollonia'da da (Sozopolis) Arianusçu hiziplerin varlığı MS IV. yüzyılda yaşamış Basileios'un mektupları sayesinde bilinmektedir ${ }^{36}$. Bu konsile Pisidia Bölgesi'nden pek çok kent iştirak etmiştir. Nikaia'da Amblada'yı Patricius $^{37}$, Baris'i Heraklios ${ }^{38}$, Limenai'yı Granius ${ }^{39}$, Metropolis'i Polykarpos ${ }^{40}$, Neapolis'i Hesykhios $^{41}$, Pappa'yı Akademios ${ }^{42}$, Seleukeia'yı Eutykhios ${ }^{43}$ temsil etmiştir. Konsilde İsa ile Tanrının tözlerinin ayrı olduğunu ileri süren Ariusçu görüş reddedilmiş ve iman esasları belirlenmiştir ${ }^{44}$. Pisidia Bölgesi'nde bu yüzyılda varlığı bilinen bir başka mezhep ise bölgenin kuzeydoğusunda bulunan Kindyria'daki Enkratite ${ }^{45}$ adlı mezheptir ${ }^{46}$. MS IV. yüzyıl yazarlarından Epiphanios, Pisidia ve Phrygia Bölgeleri'nde sayıları her geçen gün artan bu grubun varlığından eleştirel bir dille söz etmektedir. Ona göre bu mezhebin üyeleri Tatianos tarafından kandırılarak gerçek yoldan saptırılmış ve kendilerini aptallıklara adamışlardır ${ }^{47}$.

MS 325'te düzenlenen Nikaia Konsili'nden sonra Ariusçular ve karşıtları arasındaki tartışma son bulmamıştır. İki grup arasındaki sürtüşmeler 359 yılında düzenlenen ve ikiz konsiller adı

31 Talloen 2015, 201; Şahin 1994, no. 12.

32 Anastos 1967, 16-17; Kaçar 2013, 49.

33 Aydın 1998, 354.

34 Ariusçulara göre İsa ahlaki yönden öylesine büyük bir insandı ki, Tanrı onu oğlu olarak kabul etmiş ve insanların günahlarının kefareti olarak kurban etmiştir. Daha sonra Rab onu dirilterek Tanrı katına yükseltmiştir. Bu yüzden İsa tüm insanların örnek alması gereken kusursuz bir modeldi. Rubenstein 2004, 26

35 Thedor. Hist. Eccl. 1. 11-13; ayrıca bk. Kaçar 2002, 2.

36 Basil. Epist. 261. 1-11.

37 Mullen 2004, 88.

38 PG. 136, 265D; ayrıca bk. Belke-Mersich 1990, 206 s.v. Baris; Mullen 2004, 91.

39 Belke - Mersich 1990, 328 s.v. Limenai.

40 Belke - Mersich 1990, 340 s.v. Metropolis 1; Mullen 2004, 101.

41 Belke - Mersich 1990, 347 s.v. Neapolis.

42 Belke - Mersich 1990, 355 s.v. Pappa.

43 Belke - Mersich 1990, 378 s.v. Seleukeia Sidera.

44 Sinanoğlu 2001, 550.

45 Bu mezhep şehit lustinus'un öğrencisi Tatianus (yaklaşık MS 160-200) tarafından kurulmuş bir mezheptir. Tarikat evliliğe, et yemeğine ve şarhos edici içecekler içilmesine karşıydı. MS IV. yüzyılda yaşamış Kaisareialı Eusebios, bu mezhebin sapkın olduğunu ileri sürmüş ve bu mezhebin sapkın düşüncelerini Saturninus ve Markion adlı şahısların gizlice yaymaya çalıştığını ileri sürmüştür. Euseb. Eccl Hist 4. 28. 1. 1-4. 29. 3. 3; ayrıca bk.Tabbernee 2014, 293; Filipini 2017, 430.

46 MAMA 7.96.

47 Epiph. Pan. 2. 215. 2-6. 
verilen Ariminum ve Seleucia ad Calycadnum synod'larında ${ }^{48}$ devam etmiştir. Seleucia ad Calycadnum'daki konsilde Ariusçu diakonos Aetius görevinden alınmış ve imparator II Constantinus (MS 337-361) tarafından Amblada'ya sürgüne gönderilmiştir ${ }^{49}$. MS IV. yüzyılın sonunda Hristiyan alemi için sevindirici bir gelişme yaşanmıştır. Imparator Theodosius (MS 379395), Hristiyanlığı resmi din olarak ilan etmiş ve bunun sonucunda pagan tapınakları artık kiliselere dönüştürülmeye başlanmıştır. Ayrıca imparator Theodosius, Constantinus tarafından düzenlenen İznik Konsili'nde alınan kararların onaylanması ve Ariusçuluğa son darbeyi vurmak için MS 381 Constantinopolis konsilini tertiplemiştir. Theodosius'un düzenlediği bu konsile 180 piskopos iştirak etmiş, teslisçi Meletius'la Ariusçu taraflar karşı karşıya gelmiştir. İznik'te alınan kararlar bu konsilde yapılan eklemelerle son şeklini almıştır: "Her şeye gücü yeten, gögün, yerin, görülen ve görülmeyen büyün şeylerin Yaradanı olan tek bir Baba Tanrı'ya inanıyoruz. Tek Rab isa Mesih'e inanıyoruz. Tanrı́nın biricik Oğlu, ezelden beri Tanrı'dan doğan, Işık'tan gelen Işık, gerçek Tanrı'dan gelen gerçek Tanrı, yaratılmış değil, doğurulmuş, Tanrı ile aynı öze sahip olan, kendi aracılığıyla her şey yaratılmış, biz insanlar için kurtuluşumuz için göklerden inmiş, Kutsal Ruh ve bakire Meryem aracılığıla beden alıp insan olmuş, Pontius Pilatus'un emriyle bizim için çarmıha gerilmiş, sıkıntı çekmiş, gömülmüş, göklere yükselmiş, Baba'nın sağında oturmuş, dirilerle ölüleri yargılamaya görkemle gelecek O'dur. O'nun egemenliği hiç son bulmaz. Kutsal Ruh'a da inanıyoruz. Rab olan, yaşam veren, Baba'dan çıkıp gelen, Baba ve Oğul ile birlikte tapınıp yüceltilen, peygamberlerin ağzından konuşan O'dur. Havarilerin yolunda olan tek bir evrensel topluluğa inanıyoruz. Günahların bağışlanması için tek bir vaftizi tanıyoruz. Ölülerin dirilişini ve gelecek çağın yaşamını bekliyoruz" ${ }^{\prime 50}$. Bu konsilde Constantinopolis kilisesi ayrıca hiyerarşik olarak ikinci sıraya getirilmiştir ${ }^{51}$. Konsil'de Adada'yı Ananios ${ }^{52}$, Tymandos'u Kallinikos ${ }^{53}$, Konane'yi Helladios ${ }^{54}$ ve Limenai'yı Fautus ${ }^{55}$ temsil etmiştir.

MS IV. yüzyılda yaşanan gerilimler Hristiyanlar arasında sonraki yüzyıllarda da devam etmiştir. MS 428 yılında İan asıllı Nestorios Constantinopolis patrikliğine tayin edilmiştir. Nestorios göreve başladığının ilk yılında kendini Hz. Meryem'e "Theotokos-Tanrı doğuran" ve Meryem'in yalnızca bir insanın annesi (Anthropotokos) olduğunu vurgulayan gruplar arasındaki çatışmanın içinde bulmuştur. Nestorios, Theotokos unvanının kullanılmasını reddetmemiştir. Ancak bu unvanının tek başına kullanıımasının bazı sakıncaları doğuracağını öngörerek dikkatli davranmıştır. Bu yüzden "Meryem'e Mesih'i doğuran" anlamına gelen Khristotokos unvanını layık görmüştür ${ }^{56}$. Rakibi olan Khryllos, Nestorios'un fikirlerinin İsa'nın tanrılığına gölge düşüreceğine inandığı için şiddetle karşı çıkmıştır. Nestorios'un görüşlerden korkuya kapılan rakipleri MS 431 yılında Birinci Efes Konsili'ni düzenlemişlerdir ${ }^{57}$. İskenderiye ve Roma piskoposlarının önderliğinde toplanan konsilde Nestorios'un düşünceleri reddedilmiş, Meryem'e tanrı anası denmesine karar verilmiştir ${ }^{58}$. Bu konsilde Apollonia'yı Severus ${ }^{59}$, Konana'yı Prothymios ${ }^{60}$ temsil $^{\prime}$

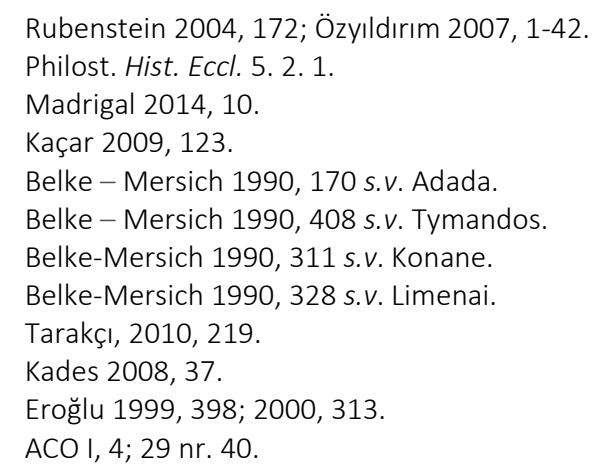


etmiştir. MS 449 da İkinci Efes Konsili toplanmıştır. Monofizit görüşün galip çıktığı bu konsilde Apollonia'yı Olympios ${ }^{61}$ temsil etmiştir. Ancak bu konsilde alınan kararlar Hristiyan alemini rahatsız etmiş, Doğu Roma imparatoru Marcianus'un davetiyle Khalkedon'da 451 yılında başka bir konsil tertip edilmiştir. Bu konsilde, MS 449'da düzenlenen 600 piskoposun iştirak ettiği ve Papa I. Leon tarafından "Haydutlar Konsili" olarak nitelendirilen Efes Konsili reddedilmiş ve $\mathrm{Hz}$. İsa'nın hem insanî hem ilâhî iki tabiata sahip olduğu görüşü kabul edilmiştir ${ }^{62}$. Ayrıca konsile iştirak etmeyen ve konsil kararlarını kabul etmeyenler Monofizit olarak adlandırılmış ve kiliseden çıkarılmışıır ${ }^{63}$. 451'deki Khalkedon konsiline, Apollonia'dan 449'daki Efes konsiline katılan Olympios ${ }^{64}$ Seleukeia Sidera'dan 458'deki Epistula ad Leonem'i imzalayan Aleksandros ${ }^{65}$ iştirak etmiştir.

MS V. yüzyı içinde bir yandan Hristiyanların kendi içindeki farklı görüşlerden doğan problemler nedeniyle sık sık konsiller toplanırken diğer yandan kentler, dinsel yapıların inşasına devam etmişlerdir. Augustus'un kurmuş olduğu kolonilerden biri olan Parlais'ta ${ }^{66}$ Posidonios, Ammaianos, Domnos, Nikias adlı diakonoslar kilisenin eukterion'unu ${ }^{67}$ (tò عúktńpıov) inşa etmişlerdir ${ }^{68}$. Kuzeybatı Pisidia Bölgesi'nde yer alan Seleukeia'da MS IV. ya da V. yüzyıla tarihlenen bir yazıtta Aziz Georgios'un ${ }^{69}$ derneğinin üyelerinden bahsedilmiştir ${ }^{70}$. Kent teritoryumunda ele geçmiş MS V. ya da VI. yüzyıla tarihlendirilen bir başka yazıtta piskopos Metrodoros'un ismi zikredilmektedir ${ }^{71}$. MS 440'da Pisidia Eyaleti'nin önemli kentlerinden Sagalasos'ta iki tapınak kiliseye dönüştürülmüştür ${ }^{72}$. Bu yazıtlarda ayrıca kilise memuriyetlerinden de bahsedilmektedir. Diğer kentlerde olduğu gibi Apollonia'da da ele geçmiş yazıtta diakonos adlı memuriyetten bahsedilmektedir.

MS VI. yüzyılda Pisidia Bölgesi, imparator lustinianus döneminde (MS 527-565) yeniden organize edilmiş ve bölge praetor düzeyinde bir vali tarafından yönetilmeye başlanmıştır ${ }^{73}$. Ayrıca bu dönemde haydut çeteleri bölgedeki halka oldukça zarar vermiş ve halk sorunun çözümü için imparator lustinianus'a başvurmuştur ${ }^{74}$. Iustinianus Dönemi'nde, Pisidia'daki kentler bir taraftan bu sorunlarla uğraşırken diğer yandan kilise çatısı altında örgütlenmelerini sürdürmüşlerdir. Iustinianus döneminde yaşamış Hierokles'in kaleme aldığı Synekdemos adlı eserde Pisidia metropolis'i Antiokheia'nın altında diğer Pisidia kentleri sıralanmıştır ${ }^{75}$. Iustinianus döne-

60 Belke-Mersich 1990, 311 s.v. Konane.

61 Belke-Mersich 1990, 387 s.v. Apollonia.

62 Harman 2002, 177.

63 Harman 2002, 177.

64 Belke-Mersich 1990, 387 s.v. Apollonia.

65 Belke-Mersich 1990, 378 s.v. Seleukeia Sidera.

66 Levick 1967, 53 vd.

67 Tapınma işlemine hizmet eden basit salon şeklindeki mekân.

68 SEG 2. 746.

69 Aziz Georgos imparator Diocletianus döneminde yaşamıs ve şehit edilmiş bir azizdir. MS 280 yılında doğmuştur. Babası Kappadokialı annesi Filistin'in Lydda şehrindendir. Imparator Diocletianus zamanında orduda asker olarak görev almış üst mertebelere haiz olmuştur. Bu dönemde Imparator'un Hıristiyan tebaa için çıkarmış olduğu fermana kendisi de bir Hıristiyan olduğu için riayet etmemiştir. Bunun sonucunda hapse atılmış, büyük işkencelere maruz kalmış ve bu sürede içinde de birçok mucize göstermiştir. En sonunda imparatorun emriyle öldürtülmüştür. Sterrett 1888a, 333, no. 465; SEG 52. 1398 [1-2]; Sterrett 1888b, 118, no. 89.

70 http://csla.history.ox.ac.uk/record.php?recid=S00259.

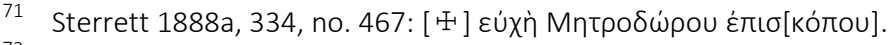

72 Akın 2012, 62.

73 Iust. Nov. 195. 15-18.

74 Iust. Nov.711. 21-712. 11.

75 Hierok. Synek. 673-1 s.v. Sozopolis; 674-2 s.v. Ioustinianoupolis; s.v. Tymandos 673-2. Bu eserde imparartorluğun 
mi, Doğu Roma imparatorluğunun (MS 527-565) iktisadi açıdan bir düzelme gösterdiği bir dönemdir. Ancak ondan sonra tahta geçen haleflerinin bazıları kendisi gibi bir başarı gösterememiştir. İmparatorluk doğu ve batıdan gelen saldırılarla düşmanların hedefi haline gelmiştir. Imparatorluk ahalisi bu meşakkatli durumda manevi kaygılarını karşılayabilmek için çok sayıda kutsal tasvirler yapmış ve bunlardan medet ummuşlardır. Öyle ki daha MS IV. yüzyılda kilise içinde tartışılmaya başlanan ikona problemi MS VII. yüzyılda ikonların yüceltilmesiyle hat safhaya ulaşmıştı. Bu durum MS VIII. yüzyılda içinden çıkılamayacak bir hal almış, insanlar tarafından mukaddes imgelere açıkça tapınılmış ve vaftiz törenlerinde lahut imgelere vaftiz anne ve baba görevi verilmiştir ${ }^{76}$. Ikona yanlılarının yarattığı bu vaziyet Küçük Asya'daki piskoposların tepkisine neden olmuştur. Bu durumu açıkça putperest bir davranış olarak gören piskoposlar bir bildiri yayınlayarak ikona karşıtı bir tutum sergilemişlerdir ve halkı bu duruma karşı uyarma misyonunu üstlenmişlerdir ${ }^{77}$. MS VIII. yüzyılda imparator III. Leon ${ }^{78}$ (MS 717-741) tasvir yanlılarına karşı öncü bir adım atmış ve Hz. İsa'nın Konstantinopolis'te yükselen altından bir heykelini yıkması için bir müfreze görevlendirmiştir ${ }^{79}$. Bu görevliler halkın tepkisiyle karşı karşıya kalmış ve olaylar sonucunda büyük ayaklanmalar vuku bulmuştur. Sadece Anadolu'da değil italya'da da ayaklanmalar baş göstermiştir. Bir zamanlar Roma İmparatorluğu'nun hüküm sürdüğü İtalya'daki ayaklanmaların arkasında Papa Gregorius'un desteği bulunmaktaydı ${ }^{80}$ Imparator, olayların şiddetlenmesinden sonra MS 730 yılında silention olarak bilinen bir kilise konsilini topladı ve kutsal tasvirlerin ortadan kaldırımasını emretti ${ }^{81}$. Halk ikona yanlıları ve ikona karşıtları (ikonoklast) diye iki gruba bölünmüştü. MS 754 yılında ikonoklastlar kendi konsillerini (Hieria Konsili) toplayarak kendilerinin düşüncelerine ters gelen ikona yanlılarının görüşlerini redderek onları aforoz etmişlerdir ${ }^{82}$ Çünkü onlara göre halkın taptığı ikonalar İsa'nın tanrısal doğasını değil insansal doğasını betimliyordu ${ }^{83}$.

MS 780 yılında ise ikona yanlılarını sevindirecek bir gelişme yaşanmıştır. Doğu Roma Imparatoru IV. Leon ölmüş (MS 775-780) ve yerine oğlu VI. Konstantinos (MS 776-796) geçmişti. Imparatorun kendisi henüz çocuk denecek yaşta olduğu için devlet idaresi imparator naibi olarak annesi Irene'ye geçmişti. Zira imparatoriçe ikona yanlısıydı ve bu durumu destekleyen doğulubatılı piskoposların bir araya gelerek bir konsil toplamasını teşvik etmiştir. MS 11 Eylül 787'de konsilin açılışı Nikaia'da yapılmıştı ${ }^{84}$. Bu konsilin toplanma gayesi ikonların doğası ve kiliselerdeki yerlerini belirleyerek ikon taraftarları ve karşıtları arasında uzun zamandan beri var olan çatışmaya son vermekti. Konsil kapsamında sekiz oturum gerçekleştirilmiştir. Anadolu'nun eyaletlerinden piskoposlar toplantıya iştirak etmişler ve birçok karar almışlardır.

Pisidia ve Lykaonia Eyaletleri beraber listelenmiş ancak Lykaonia Eyaletinden çok az piskopos konsile iştirak etmiştir.

Aşağıdaki tabloda Pisidia metropolisi Antiokheia'nın altında konsile katılan Pisidia kentleri verilmiştir ${ }^{85}$.

64 eyaletinden 912 şehir listelenmiştir

76 Norwich 2013, 288.

77 Norwich 2013, 288.

78 Theop. Chron. 391; ayrıca bk. Vasiliev 1943, 297; Ostrogorsky 2011, 144; Norwich 2013, 284.

79 Theop. Chron. 405. 1-14; ayrıca bk. Norwich 2013, 289.

80 Theop. Chron. 408. 21-25; ayrıca bk. Levtchenko 2007, 143; Norwich 2013, 289.

81 Theop. Chron. 408. 28-409. 7; ayrica bk. Atkinson 1973, 52; Norwich 2013, 299.

82 Theop. Chron. 427. 28-428. 2; ayrıca bk. Madricgal 2014, 25.

83 Madricgal 2014, 25.

84 Theop. Chron. 462. 17-462.25; ayrıca bk. Darrouzès 1975, 5; Iversen 2012, 109.

85 Tablo Darrouzès 1975, 50'den alıntılanmıştır. 

A. Birinci oturum
B. İkinci oturum (26 Eylül)
D. Dördüncü oturum (1 Ekim)
E. Yedinci oturum (13 Ekim)
F. Yedinci oturumun özeti

Tablo 1. 787 Nikaia Konsili'ne katılan Pisidia Kentleri

\begin{tabular}{|l|l|c|c|c|c|c|}
\hline Kent & Piskopos & A & B & D & E & F \\
\hline Philomelion & Sisinnios & 228 & 219 & 281 & 280 & 264 \\
\hline Pappa & Mikhael & 229 & 221 & 282 & 281 & 263 \\
\hline Tymbriada & lohannes & - & - & - & 504 & 265 \\
\hline Sagalassos & lohannes & 230 & 222 & 287 & 286 & - \\
\hline Apameia K. & Sisinnios & 231 & 223 & 283 & 282 & - \\
\hline Konata & Constantin & 232 & 224 & 284 & 283 & - \\
\hline Adada & Nikephoros & 233 & - & 285 & 284 & - \\
\hline Tiyassos & Petros & 234 & - & 286 & 285 & - \\
\hline Baris & Leon & 235 & - & 288 & 287 & - \\
\hline Seleukeai P. & Petros & 236 & - & 289 & 288 & - \\
\hline Sozopolis & Leon t. & 237 & 225 & - & - & - \\
\hline
\end{tabular}

Tabloda Pisidia kentlerinin A, D, E oturumlarına büyük çoğunluğunun katıldığı, B ve $F$ oturumlarına çoğunluğun iştirak etmediği görülmektedir.

Kuzey Pisidia Bölgesi'nde Hristiyanlık Paulus ve yoldaşlarının çabalarıyla MS I. yüzyılda yeşermeye başlamış diğer bölgelerde olduğu gibi sonraki yüzyıllarda yayılmayı sürdürmüştür. Paulus'un bölgeye ziyarette bulunmasının en büyük nedenlerinden biri buradaki Yahudi nüfusunun varlığıdır. Zira Antiokheia'da bulunan sinagogtan antik kaynaklar bahsetmektedir. Bunun dışında Seleukeaia Sidera bulunmuş yazıtlarda Yahudi isimleri geçmektedir ${ }^{86}$. Olasılıkla kentte Yahudiler yaşamaktaydi ${ }^{87}$. Bölgedeki Yahudi nüfusundan haberdar olan azizler bölgeye gelmiş ve halkı Hristiyanlığa davet etmişlerdir. MS III. yüzyılda bölgede Hristiyanlıkla ilgili yazıtlara çok sık rastlanılmamaktadır. Bu durum, bölgedeki yüzey araştırmaları ve arkeolojik kazıların sayııının azlığından kaynaklanabileceği gibi yönetim erkinin Hristiyanlara uyguladığı zulümlerden dolayı Hristiyanların bu tarihlerde kendilerini gizlemiş olmalarına da bağlanabilir. Bu baskılar altında Hristiyanlar ya kendilerini inkâr etmek zorunda kalmış ya da öyle görünmek istemiş olmalıdırlar. Diocletianus'un başa geçmesiyle diğer bölgelerde olduğu gibi Pisidia Bölgesindeki Hristiyanlar da büyük bir katliama uğramışlardır. MS 311-313 yılları arasında Pisidia Eyaleti valisi Valerius Diogenes'in döneminde katliamlar oldukça fazladır. Hristiyanlığın resmi din olarak benimsenmesiyle kilise örgütleri devlet bünyesinde gittikçe erk sahibi olmuş ve ilerleyen yüzyıllarda bu durum aynı şekilde kilise yönetiminin lehine süregelmiştir. Hristiyanlığın diğer dinlerle eşit statüye kavuşmasından sonra kiliseler giderek siyasi ve ekonomik açıdan büyük güçler elde etmiştir. Hristiyanlığın yayılmasıyla birlikte bölgede MS II. yüzyıldan itibaren farklı Hristiyan cemaatlerin ortaya çıktığı görülmektedir. Ariusçular, Montanistler ve Enkratite mezhepleri bunlar arasındadır. Ayrıca imparatorluk genelinde MS IV. yüzyılda Hristiyan gruplar arasındaki görüş ayrılıkları giderek şiddetlenmiş, yönetim ve din adamları bu görüş ayrılıklarına bir son vermek için sık sık konsiller toplamışlardır. Bunun sonucunda eyaletlerde bulunan piskoposlar toplanan bu konsillere temsilci göndermişlerdir. Kuzey Pisidia'da bulunan Apollonia, Seleukeia, Konana ve Tymandos bu konsillerin bazılarına iştirak etmiştir. Bu kentlerde bulunan yazıtlar MS V. ve VI. yüzyıllarda

86 Kent yazıtlarında Iohannes ve Abramis gibi Yahudi isimleri geçmektedir. Sterrett 1888a, 333 no. 465; 1888b, 118 no. 89.

87 Talloen 2015, 203. 
kentlerin artık Hristiyan bir yapıya büründüğünü göstermektedir.

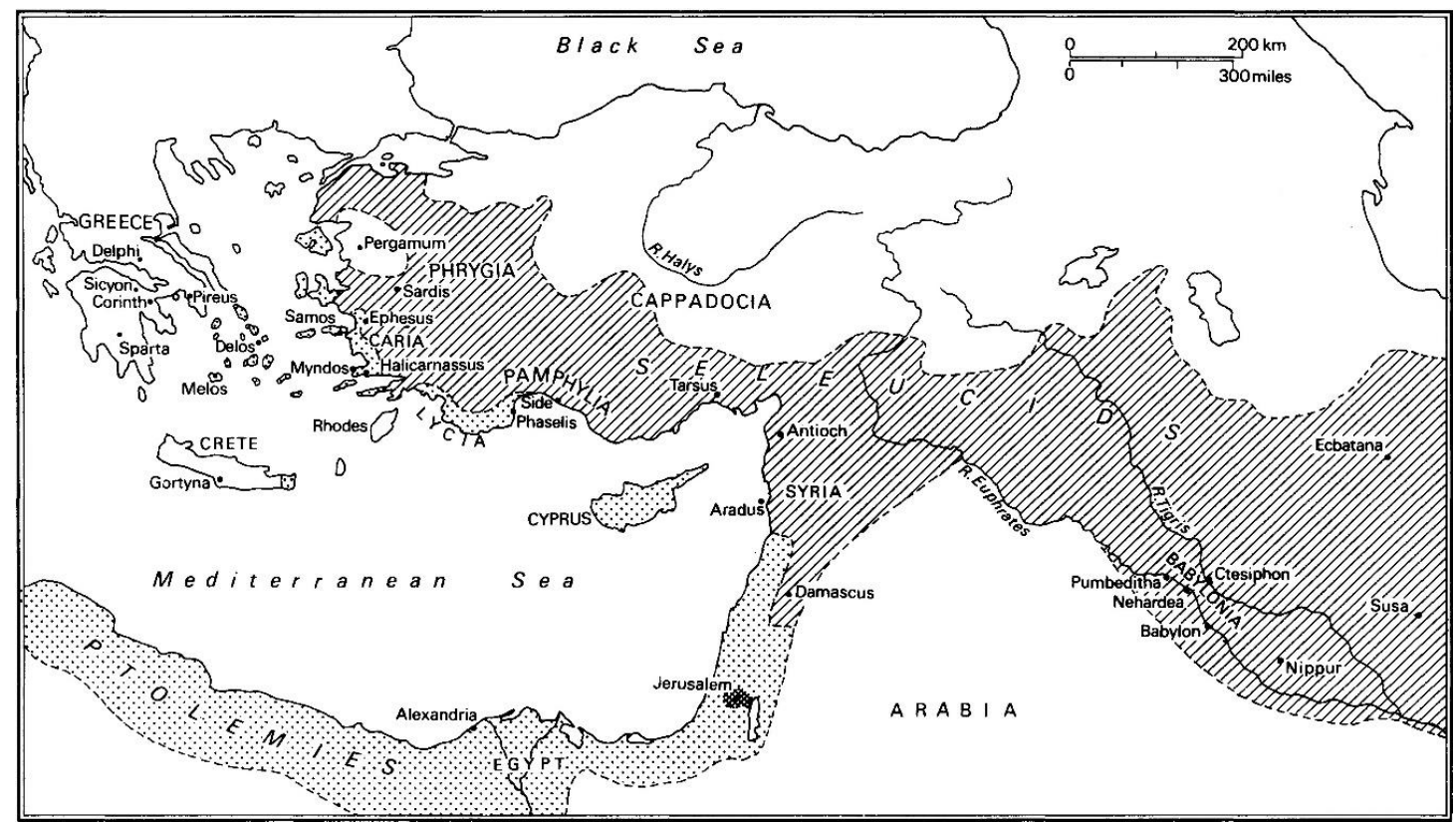

Fig. 1. MÖ III. ve I. yüzyıllarda Babil, Küçük Asya ve Hellas'taki Yahudi diasporası. Hegermann 1989, 147.

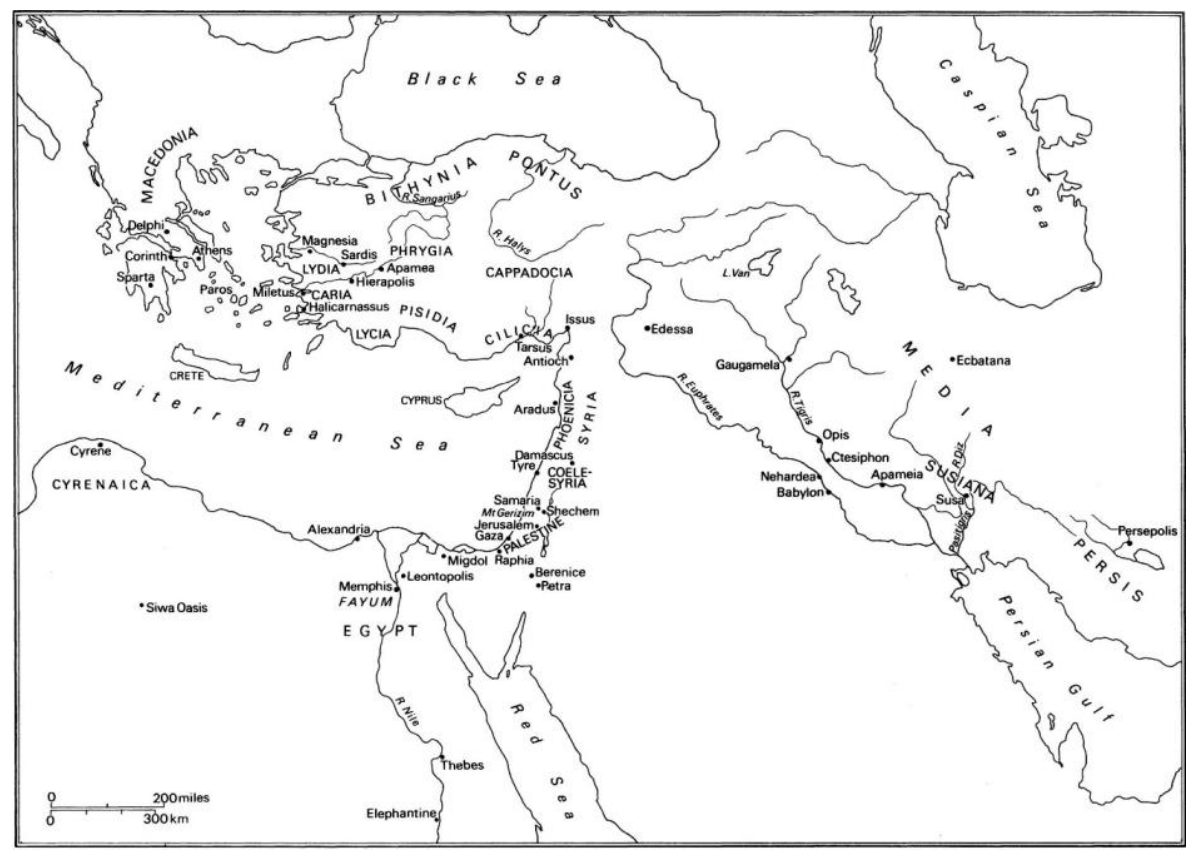

Fig. 2. Hz. İsa döneminde Yahudi diasporası. Hegermann 1989, 118-119. 


\section{BIBBLIYOGRAFYA}

\section{Antik Kaynaklar}

Acta Apost.

Basil. Epist.

Epiph. Pan.

Epist. Paul. Ad Coloss.

Euseb. Eccl. Hist.,

Georg. Syn. chron.

Hierok. Synek.

Ignat. Scr. Eccl. Epist.

lust. Nov.

Philost. Hist. Eccl.

Plin. Epist.

Prop. Vit.

Suet. Nero.

Tac. Ann.

Theodor. Hist. Eccl.

Theop. Chron.

Modern Literatür

ACO

Adıbelli 2013

Akın 2012
Acta Apostolorum. Kullanılan Metin ve Çeviri: The Greek New Testament, Eds., K. Aland - M. Black - C. M. Martini - B. M. Metzger - A. Wikgren. Stuttgart $\left(1968^{2}\right)$ 416-528.

(= Basileos, Epistulae) Kullanılan Metin ve Çeviri: Saint Basile, Lettres. Vols. 3, Edt.: Y. Courtonne, Paris 1966.

Epiphanius, Panarion (Adeversus Haereses) Epiphanius, Kullanılan Metin ve Çeviri: Bände 1-3: Ancoratus und Panarion, Die griechischen christlichen Schriftsteller. Edt.: K. Holl. Leipzig 1915.

Epistula Pauli ad Colossenses, The Greek New Testament. Eds.: K. Aland M. Black - C. M. Martini - B. M. Metzger - A. Wikgren. Stuttgart 1968.

(= Eusebios, Historia Ecclesiastica), Kullanılan Metin ve Çeviri: Eusebe de Cesaree. Histoire ecclesiastique. 3 vols. Edt.: G. Bardy. Paris 1967.

(= Georgios Syncellus, Ecloga Chrongraphica). Kullanılan Metin ve Çeviri: Ecloga chronographica. Edt. A. A. Mosshammer, Leipzig 1984.

(= Hieroclis Synecdemus) Kullanılan Metin: Hieroclis Synecdemus et notitiae Graecae episcopatuum. Edt. G. Parthey, Amsterdam 1967.

(= Ignatus, Epistulae vii genuinae) Ignace d'Antioche. Polycarpe de Smyrne. Kullanılan Metin ve Çeviri: Lettres. Martyre de Polycarpe. Edt.: P. T. Camelot. Paris 1969.

(= Novellae lustinianii) Kullanılan Metin ve Çeviri: Corpus iuris civilis 3, Eds. R. Scholl - W. Kroll. Berlin 1895.

(= Philostorgius, Historia Ecclesiastica) Kullanılan Metin ve Çeviri: Philostorgius. Kirchengeschichte Edt. F. Winkelmann. Berlin 1981.

(= Gaius Plinius Caecilius Secundus, Epistulae) Kullanılan Metin ve Çeviri: Genç Plinius'un Anadolu Mektupları 10 kitap. Çev.: Ç. Dürüşken - E. Özbayoğlu, İstanbul 1999. (Yapı Kredi Yayınları)

(= Prophetarum vitae fabulosae) Kullanılan Metin ve Çeviri: Index apostolorum discipulorumque Domini (textus Pseudo-Dorothei). Edt. T. Schermann. Leipzig 1907.

(= Gaius Suetonius Tranquillus, de Vita Caesarum) Kullanılan Metin ve Çeviri: Gaius Suetonius Tranquillus, On Iki Caesar'ın Yaşamı. Çev.: F. Telatar ve G. Özaktürk. Ankara 2008. (Türk Tarih Kurumu Yayını).

(= Tacitus, Annales) Kullanılan Metin ve Çeviri: Tacitus, Annals. Trans.: J. Jackson. Cambridge-Massachusetts 1937. (The Loeb Classical Library).

(= Theodoretos, Historia ecclesiastica). Kullanılan Metin ve Çeviri: Die griechischen christlichen Schriftsteller. Eds.: L. Parmentier - F. Scheidweiler. Berlin 1954.

(= Theophanes, Chronographia) Kullanılan Metin ve Çeviri: Theophanis Chronographia 1. Edt. C. Boor. Leipzig 1883.

Acta Conciliorum Oecumenicorum. Tomus I: Concilium Universale Ephesenum. Volumen I: Acta Graeca. Pars I: Collectio Vaticana. 1-32 Edt. E. Schwartz - S. Johannes, Berolini 1927.

R. Adıbelli, "Doğu Hıristiyanlarının Bugünkü Durumuna Genel Bir Bakış". Milel ve Nihal Inanç, Kültür ve Mitoloji Araştırmaları Dergisi 10/2 (2013) 133-172.

Y. Akin, is. III. - V. Yüzyıllarda Pamphylia Kentlerindeki Toplumsal 
Anastos 1967

Atkinson 1973

Aydın 1998

Aydın 2002

Barclay 1996

Belke - Mersich 1990

BHG

Calder 1955

CIG

Darrouzès 1975

Eroğlu 1999

Eroğlu 2000

Eyice 2002

Filipini 2017

Fox 2006

Gwynn 2015

Harman 2002

Hegermann 1989

ILS

Iversen 2012

Kaçar 2002

Kaçar 2009

Kaçar 2013,

Kades 2008
Değişimler. Yayımlanmamış Yüksek Lisans Tezi, Akdeniz Üniversitesi SBE. Antalya 2012.

M. V. Anastos, "The Edict of Milan (313): A Defence of its Traditional Authorship and Designation". Revue des études byzantines 25 (1967) 1341.

J. Atkinson, "Leo III and Iconoclasm". Theoria: A Journal of Social and Political Theory 41 (1973) 51-62.

M. Aydın, "Hıristiyanlık Mezhepler ve Tarikatlar". TDVIA 17 (1998) 353-358.

M. Aydın, "Konsillerin Hıristiyanlıktaki Yeri ve Önemi". Dinler Tarihi Araştırmaları III (2002) 107-117.

J. M. G. Barclay, Jews in the Mediterranean Diaspora: From Alexander to Trajan (323 BCE 117 CE). Edinburgh 1996.

K. Belke - N. Mersisch, Tabula Imperii Byzantini 7, Phrygien und Pisidien. Wien 1990.

Bibliotheca Hagiographica Graeca. Edt. F. Halkin, (Bibliotheca Hagiographica Graeca (Société des Bollandistes), Brüksel 1957.

W. M. Calder, "Early-Christian Epitaphs from Phrygia". Anatolian Studies 5 (1955) 25-38.

Corpus Inscriptionum Graecarum. Edt. A. Böckhe, Corpus Inscriptionum Graecarum, Berlin 1828-1877.

J. Darrouzès, "Listes épiscopales du concile de Nicée (787)". Revue des études Byzantines 33 (1975) 5-76.

A. H. Eroğlu, "Doğu Batı Kiliselerinin Ayrılış Sebepleri". Dini Araştırmalar 2/5 (1999) 387-413.

A. H. Eroğlu, "Hıristiyanların Bölünme Sürecine Genel Bir Bakış". Ankara Üniversitesi Illahiyat Fakültesi Dergisi 41/1 (2000) 309-325.

S. Eyice, "Thekla at Antioch". Eds.T. Drew-Bear - M. Taşlıalan - C. M. Thomas Actes du ler congres international sur Antioche de Pisidie. Lyon (2002) 111-122.

A. Filipini, "Non sono atti degli apostoli ma scritti demoniaci. II movimento enkratita nell'Anatolia tardoantica: iscrizioni, eresiologi e testi apocrifi". Asia Minor Studien 86 (2017) 413-472.

R. L. Fox, Pagans and Christians. New York 2006.

C. M. Gwynn, Christianity in the Later Roman Empire: A Sourcebook. London 2015.

Ö. F. Harman, "Konsil” TDVIA 26 (2002) 175-178.

$\mathrm{H}$. Hegermann, "Diaspora in the Hellenisctic Age". The Cambridge History of Judaism. Eds. W. D. Davies - L. Finkelstein. Cambridge (1989) 115-166. Inscriptiones Latinae Selectae. I-III. Edt. H. Dessau, Berlin

P. A. Iversen, "Inscriptions from Pisidian Konane (Conana) and the Surrounding Area". Epigraphica Anatolica 45 (2012) 104-152.

T. Kaçar, "Roma İmparatorluğun'da Kilise Konsillerinin Siyasallaşması: İznik Örneği”. Anadolu Üniversitesi Sosyal Bilimler Dergisi II/1 (2002) 1-18.

T. Kaçar, "Konstantinopolis Kilisesinin Kuruluşu: Mitoloji ve Tarih". Güneydoğu Avrupa Araştırmaları Dergisi 14 (2009) 115-137.

T. Kaçar "Roma İmparatorluğu, Hıristiyanlar ve Milano Fermanı'nın 1700. Yılı". Toplumsal Tarih Dergisi 230 (2013) 46-50.

T. Kades, Der Dialog zwischen Christen und Muslimen im Spannungsfeld von Tradition und Moderne XXI. Berlin 2008. 
Kaşka 2017

Katar 2007

Lenski 2016

Levick 1967

Levine 1999

Levtchenko 2007

Madrigal 2014

MAMA

Mitchell 1988

Mullen 2004

Norwich 2013

Ostrogorsky 2011

Özyıldırım 2007

Parker 2013

$P G$

Ramsay 1897

Rives 1999

Robinson 1926

Rubenstein 2004

Ruggieri - Filipović 2007

Schaff 2002

Schalit 1960

SEG

Sinanoğlu 2001

Sodini 2014

Sönmez 2015

Stephenson 2016

Sterrett 1888a

Sterrett $1888 \mathrm{~b}$
G. Kaşka, "Pisidia Antiokheia'sında Hristiyanlık", SDÜ Fen-Edebiyat Fakültesi Sosyal Bilimler Dergisi 41 (2017) 21-33.

M. Katar, "Tevhitten Teslise Geçiş Sürecinde Hıristiyanlık (Bir Yahudi ỉhya Hareketi Olarak Başlayan Hıristiyanlığın Evrensel Bir Din Haline Geliş Öyküsü)". Journal of Islamic Research 20/3 (2007) 330-339.

N. Lenski, Constantine and the Cities: Imperial Authority an Civic Politics. Philadelphia 2016.

B. Levick, Roman Colonies in Southern Asia Minor. Oxford 1967.

L. I. Levine, "The Hellenistic-Roman Diaspora ce 70-ce 235: The Archaeological Evidence". Eds. W. Horbury - W. D. Davies - J. Sturdy, The Cambridge History of Judaism 3. Cambridge (1999) 991-1024.

M. V. Levtchenko, Bizans Tarihi. Çev.: Maide Selen. İstanbul 2007.

M. Madrigal, Anadolu'nun Ekümenik Konsilleri. İstanbul 2014.

Monumenta Asiae Minoris Antiqua. Manchester 1928-.

S. Mitchell, "Maximinus and the Christians in A.D. 312: A New Latin Inscription". JRS 78 (1988) 105-124.

R. L. Mullen, The Expansion of Christianity A Gazetteer of its First Three Centuries. Leiden-Boston 2004.

J. J. Norwich, Bizans: Erken Dönem (MS. 323-802). Çev.: Hamide Koyukan. İstanbul 2013.

G. Ostrogorsky, Bizans Tarihi. Çev.: Fikret Işıltan. Ankara 2011.

M. Özyıldırım, "Ariminum ve Seleucia ad Calycadnum Konsilleri, 359 İkiz Konsiller Yılı". Olba XV (2007) 1-42.

B. Parker, "Works of the Law and the Jewish Settlement in Asia Minor". JGRChJ 9 (2013) 42-96.

Patrologia Graeca. Edt. J. P. Migne, 1-161, Paris 1857-1866.

W. M. Ramsay, Cities and Bishoprics of Phrygia Being an Essay of the Local History of Phyrygia from the Earliest Times to the Turkish Conquest I-II. Oxford 1895-1897.

J. B. Rives, "The Decree of Decius and the Religion of Empire". JRS 89 (1999) 135-154.

D. M. Robinson, "Greek and Latin Inscriptions from Asia Minor". TAPhA 57 (1926) 195-237.

R. E. Rubenstein, İsa Nasıl Tanrı Oldu?. Çev.: Cem Demirkan. İstanbul 2004.

V. Ruggieri - A. Filipović, "Antiochia di Pisidia Qualche considerazione epigrafica e liturgica". La Parola del Passato 157 (2007) 451-468.

P. Schaff, History of the Christian Church Volume I: Apostolic Christianity. A.D. 1-100. New-York 2002.

A. Schalit, "The Letter Antiochus III to Zeuxis Regarding the Establishment of Jewish Military Colonies in Phrygia an Lydia". JQR 50/4 (1960) 289-318.

Supplementum Epigraphicum Graecum. Leiden et al. 1923.

M. Sinanoğlu, "iznik Konsili". TDViA 23 (2001) 549-552.

J. P. Sodini, "Küçük Asya”. Bizans Dünyası. Doğu Roma imparatorluğu 330641. Çev.: A. Bilge. İstanbul 2014.

S. Sönmez, "Manastırların Sosyokültürel Yapı ve Fonksiyonları". A. Ü. Türkiyat Araştırmaları Enstitüsü Dergisi [TAED] 54 (2015) 693-711.

P. Stephenson, Büyük Konstantin. Çev.: Gürkan Ergin. İstanbul 2016.

J. R. S. Sterrett, The Wolfe Expedition to Asia Minor. Boston 1888.

J. R. S. Sterrett, An Epigraphical Journey in Asia Minor. Boston 1888. 
Şahin 1994

Şişman 2001

Tabbernee 2014

Talloen 2015

TAM

Tarakçı 2010

Tiefenbach 2012

Trebilco 1994

Vasiliev 1943
S. Şahin, Die Inschriften von Arykanda. Bonn 1994.

A. Şişman, “Misyonerlik Faaliyetleri ve Uşak'ta Montanizm'e Dair Çalışmalar". Afyon Kocatepe Üniversitesi Sosyal Bilimler Dergisi 3/2 (2001) 1-6.

W. Tabbernee, Early Christianity in Context An Exploration: Across Cultures and Continents. Michigan 2014.

P. Talloen, Cult in Pisidia. Religious Practice in Southwestern Asia Minor from Alexander the Great to the Rise of Christianity. Studies in Eastern Mediterranean Archaeology 10. Brepols (2015).

Tituli Asiae Minoris. I-V, Vien 1901-1981.

M. Tarakçı, "Nestorius ve Kristolojisi”. Uludağ Üniversitesi Ilahiyat Fakültesi Dergisi 19/1 (2010) 215-241.

H. Tiefenbach, Anadolu'nun Azizleri. İstanbul 2012.

P. R. Trebilco, Jewish Communities in Asia Minor. Cambridge 1994.

A. A. Vasiliev, Bizans imparatorluğu Tarihi. Çev.: Arif Müfid Mansel. Ankara 1943. 